\title{
氮添加对内蒙古温带草原羊草光合特性的影响
}

\author{
翟占伟 ${ }^{1}$ 龚吉荵 ${ }^{*}$ 罗亲普 ${ }^{1}$ 潘 琰 ${ }^{1}$ 宝音陶格涛 ${ }^{2}$ 徐 沙 $^{1}$ 刘 敏 ${ }^{1}$ \\ 杨丽丽 1
}

${ }^{1}$ 北京师范大学地表过程与资源生态国家重点实验室, 北京师范大学地理科学学部资源学院, 北京 $100875{ }^{2}$ 内蒙古大学生命科学学院, 呼和浩特 010021

\begin{abstract}
摘 要 受人类活动和气候变化的影响, 大气氮 $(\mathrm{N})$ 沉降日益加剧, 使得草地生态系统正从自然 $\mathrm{N}$ 限制转向富营养化甚至饱 和, 进而影响了草地的生长。然而, 关于优势种植物在 $N$ 添加下的光合生理潜在机制的研究仍然不足。该研究以内蒙古温带 典型草原优势种植物为研究对象, 通过不同水平的 $\mathrm{N}$ 养分添加实验, 探讨优势种羊草(Leymus chinensis)对 $\mathrm{N}$ 添加的光合生理 响应机制。结果表明: 地上生物量随着 $\mathrm{N}$ 添加先增加后降低, 以 $10 \mathrm{~g} \mathrm{~N} \cdot \mathrm{m}^{-2} \cdot \mathrm{a}^{-1}$ 处理增加最多。尽管 $25 \mathrm{~g} \mathrm{~N} \cdot \mathrm{m}^{-2} \cdot \mathrm{a}^{-1}$ 处理出现下 降趋势, 但与对照相比仍然显著增加了地上生物量。低 $N$ 时, 植物通过把较少的 $N$ 分配给羧化系统, 并降低比叶质量 $(L M A)$ 使 叶片获得更多的光能来适应低N生境。适量的N添加通过增加总叶绿素(Chl)的含量, 降低Chl a/b的比值来捕获更多光能; 同时 增加 $L M A$ 、羧化效率、最大羧化速率 $\left(V_{\mathrm{cmax}}\right)$ 、最大电子传递速率 $\left(J_{\max }\right)$, 并降低 $J_{\max } / V_{\mathrm{cmax}}$, 把更多的 $\mathrm{N}$ 分配给羧化系统, 提高羧 化能力; 通过增加实际光化学效率、电子传递效率和光化学猝灭系数, 提高了光系统II (PSII)的光化学活性。过量的N添加对 羊草的生理指标有一定抑制作用, 羧化能力降低, 导致净光合速率有所降低, 在一定程度上抑制PSII的光化学活性, 而非光 化学猝灭系数以及类胡萝卜素增加起到了耗散过剩激发能的作用。N添加对羊草光合特性的影响总体表现为“适量促进, 过量 抑制”。该地区羊草最适的 $\mathrm{N}$ 添加范围是 $5-10 \mathrm{~g} \mathrm{~N} \cdot \mathrm{m}^{-2} \cdot \mathrm{a}^{-1}$ 。
\end{abstract}

关键词 氮添加; 温带草原; 羊草; 光合特性; 光合色素

引用格式: 翟占伟, 龚吉荵, 罗亲普, 潘琰, 宝音陶格涛, 徐沙, 刘敏, 杨丽丽 (2017). 氮添加对内蒙古温带草原羊草光合特性的影响. 植物生态学报, 41, 196-208. doi: 10.17521/cjpe.2016.0128

\section{Effects of nitrogen addition on photosynthetic characteristics of Leymus chinensis in the tem- perate grassland of Nei Mongol, China}

ZHAI Zhan-Wei ${ }^{1}$, GONG Ji-Rui ${ }^{1 *}$, LUO Qin-Pu ${ }^{1}$, PAN Yan ${ }^{1}$, BAOYIN Taogetao ${ }^{2}$, XU Sha ${ }^{1}$, LIU Min $^{1}$, and YANG $\mathrm{Li}-\mathrm{Li}^{1}$

${ }^{1}$ Laboratory of Earth Surface Processes and Resource Ecology, Beijing Normal University, College of Resources Science \& Technology, Faculty of Geographical Science, Beijing Normal University, Beijing 100875, China; and ${ }^{2}$ College of Life Sciences, Inner Mongolia University, Hohhot 010021, China

\section{Abstract}

Aims The increased atmospheric nitrogen (N) deposition due to human activity and climate change greatly causes grassland ecosystems shifting from being naturally $\mathrm{N}$-limited to $\mathrm{N}$-eutrophic or $\mathrm{N}$-saturated, and further affecting the growth of grass species. The aims of this study are: 1) to evaluate the effects of different $\mathrm{N}$ addition levels on morphology and photosynthetic characteristics of Leymus chinensis; 2) to determine the critical $\mathrm{N}$ level to facilitate $L$. chinensis growth.

Methods We conducted a different $\mathrm{N}$ addition levels experiment in dominant species in the temperate steppe of Nei Mongol. The aboveground biomass, morphological and leaf physiological traits, pigment contents, chlorophyll a fluorescence parameters and biochemical parameters of $L$. chinensis were investigated.

Important findings Our results showed that aboveground biomass first increased and then decreased with the increased $\mathrm{N}$, having the highest values at the $10 \mathrm{~g} \mathrm{~N} \cdot \mathrm{m}^{-2} \cdot \mathrm{a}^{-1}$ treatment, but the $25 \mathrm{~g} \mathrm{~N} \cdot \mathrm{m}^{-2} \cdot \mathrm{a}^{-1}$ still significantly increased the aboveground biomass relative to $0 \mathrm{~g} \mathrm{~N} \cdot \mathrm{m}^{-2} \cdot \mathrm{a}^{-1}$. Leymus chinensis accommodate low $\mathrm{N}$ situation through allocating less $\mathrm{N}$ to carboxylation system and decreasing leaf mass per area (LMA) in order to get more light energy. Moderate $\mathrm{N}$ addition captured more light energy through increasing total chlorophyll (Chl) contents and decreasing the ratio of $\mathrm{Chl}$ a/b. Moderate $\mathrm{N}$ addition increased $L M A$, carboxylation efficiency, maximum car-

收稿日期Received: 2016-04-07 接受日期Accepted: 2016-12-25

* 通信作者Author for correspondence (E-mail: jrgong@bnu.edu.cn) 
boxylation rate ( $\left.V_{\text {cmax }}\right)$, maximum electron transport rate $\left(J_{\max }\right)$ and decreased $J_{\max } / V_{\text {cmax }}$, thus allocating more $\mathrm{N}$ to carboxylation system to enhance carboxylation capability. Moreover, the photochemical activity of PSII was increased through higher effective quantum yield of PSII photochemistry, electron transport rate and photochemical quenching coefficient. Excessive $\mathrm{N}$ addition had negative effects on physiological variables of $L$. chinensis due to lower carboxylation capability and photochemical activity of PSII, further leading to decreased net photosynthetic rate, whereas increased non-photochemical quenching coefficient and carotenoids played the role in the dissipation of excess excitation energy. Overall, moderate $\mathrm{N}$ addition facilitated the photosynthetic characteristics of dominant species, but excessive $\mathrm{N}$ addition inhibited photosynthetic characteristics. The most appropriate $\mathrm{N}$ addition for the growth of $L$. chinensis was $5-10 \mathrm{~g} \mathrm{~N} \cdot \mathrm{m}^{-2} \cdot \mathrm{a}^{-1}$ in the temperate steppe of Nei Mongol, China.

Key words nitrogen addition; temperate grassland; Leymus chinensis; photosynthetic characteristics; photosynthetic pigments

Citation: Zhai ZW, Gong JR, Luo QP, Pan Y, Baoyin T, Xu S, Liu M, Yang LL (2017). Effects of nitrogen addition on photosynthetic characteristics of Leymus chinensis in the temperate grassland of Nei Mongol, China. Chinese Journal of Plant Ecology, 41, $196-208$. doi: 10.17521/cjpe.2016.0128

在陆地生态系统中, 氮 $(\mathrm{N})$ 元素不仅是植物需 求量最大的营养元素, 也是植物生长和光合作用的 主要限制因子(Zhao \& Liu, 2009; Krause et al., 2012; Wang \& Liu, 2014; Du et al., 2016)。近年来, 受人类 活动和气候变化的影响, 我国北方草地生态系统的 结构和功能受到长期过度放牧的影响而严重退化, 并且表现为土壤中可利用性 $\mathrm{N}$ 严重不足, 其生态系 统不同组织水平对于 $\mathrm{N}$ 输入的变化较其他生态系统 更为敏感(王仁忠, 1997; 陈佐忠和汪诗平, 2000; 王 玉辉等, 2002; Zhang \& Han, 2008; Liu et al., 2011; 白雪等, 2014; Chen et al., 2015)。而大气N沉降日益 加剧, 使得土壤中可利用性 $\mathrm{N}$ 显著增加(Clark \& Tilman, 2008; Du et al., 2014)。N沉降可以缓解生态 系统的N限制, 促进植物光合作用, 提高植物的生 产力和碳储存(Aber et al., 2003; Bai et al., 2009)。N 添加是恢复退化草地生态系统的一种有效手段(詹 书侠等, 2016)。因此, 研究草原植被对养分添加的 响应和适应机制对草地生态系统的管理和恢复具有 重要意义。

近年来我国草地陆续开展了较多 $\mathrm{N}$ 沉降生态环 境效应的试验研究, 并取得了显著的研究成果, 但 相关研究基本上还局限在植物生长、生物多样性、 生态系统碳水交换、土壤呼吸、 $\mathrm{N}$ 素转化、调落物 分解以及土壤微生物及养分变化等方面(潘庆民等, 2005; Liu et al., 2011; Peng et al., 2014; Sun et al., 2014), 针对N沉降对生态系统不同组织水平的影响 开展的研究成果还少有报道, 例如主要优势种和建 群种光合及生理生态特性对 $\mathrm{N}$ 沉降变化响应的试验
更为鲜见，并且相关机制尚不清楚(白雪等，2014)。 优势种是草地生态群落的重要组成部分, 虽然物种 数较少, 但在群落生物量上的分配比例较大, 在一 定程度上决定了草地生态系统的属性(Mariotte et al., 2012)。群落结构对环境做出的响应是优势种变 化的集中体现，而优势种的生理生态反应机制影响 着群落结构和生态系统对环境变化的响应(Liu et al., 2012; 张梓瑜等, 2013)。因此, 了解优势种对N添加 的生理生态响应是理解草地生态群落和生态系统过 程的关键, 能真实地反映不同 $\mathrm{N}$ 添加浓度下优势种 对气候环境因子变化的响应(Anderson et al., 2006; Makhnev \& Makhneva, 2010)。羊草(Leymus chinensis) 是我国温带草原生态系统的优势种, 为多年生根茎 型的 $\mathrm{C}_{3}$ 植物, 具有适口性好、营养价值高的特点 $(\mathrm{Xu}$ \& Zhou, 2006)。目前, 关于N添加对羊草影响的研究 主要集中在化学计量关系、N水利用效率权衡机制、 地上地下生物量分配、微生物群落结构和功能、根 系存活和寿命以及营养再吸收(Bai et al., 2008; Zhang et al., 2010; Xiao et al., 2011; Li et al., 2014; Yao et al., 2014; Zhang et al., 2016)。羊草对N添加的 生理生态响应机制也因施肥剂量、实验地点以及时 间长短而异(Chen et al., 2005; 肖胜生等, 2010; 白 雪等, 2014; 詹书侠等, 2016)。因此, 有必要进一步 探讨羊草光合特性对 $\mathrm{N}$ 添加的响应机制。

叶绿素在绿色植物光合作用中发挥着重要作用, 实现光能到化学能的转化, 为碳同化积累同化力 (张云海等, 2013)。叶绿素苂光对研究光系统对光能 的吸收、传递、耗散、分配等具有独特的作用, 可 
以反映植物光合作用与环境之间相互关系的内在特 性(李晓等, 2006)。 $\mathrm{N}$ 元素是光合器官的组成成分, 叶片中有 $30 \%-40 \%$ 的 $\mathrm{N}$ 参与到羧化反应中, 其中分 配给羏化系统的 $\mathrm{N}$ 元素比例决定了最终的光合效率, 而叶片缺 $\mathrm{N}$ 将导致植物光合速率、光合量子效率和 与碳代谢相关的酶类活性降低, 影响着植物叶片最 大羧化速率 $\left(V_{\mathrm{cmax}}\right)$ (Warren et al., 2000; 郭二辉等, 2008; Nicodemus et al., 2008; 朱军涛等, 2010)。然而, 关于解释 $\mathrm{N}$ 沉降影响植物生长的光合生理机制仍有 争论。土壤 $\mathrm{N}$ 含量主要受 $\mathrm{N}$ 沉降的速率和持续时间的 影响, 而一些地区正从自然状态下的 $N$ 限制转向富 营养化甚至饱和(Aber et al., 2003; Krause et al., 2012)。而N沉降对植物生长的促进和抑制作用均有 报道, 可能主要依赖于 $\mathrm{N}$ 沉降是否引起了 “ $\mathrm{N}$ 饱和” (Wallace et al., 2007; Zhao \& Liu, 2009; Thomas et al., 2010)。因此, 有必要确定当地是否出现了 “N饱和” 以及羊草最适合的施 $\mathrm{N}$ 量。

鉴于此, 本文以不同水平 $\mathrm{N}$ 添加下内蒙古温带 典型草原优势种羊草为研究对象, 通过测定羊草地 上生物量、比叶质量、叶片 $\mathrm{N}$ 含量、水分利用效率、 气体交换参数、叶绿素苂光参数和 $\mathrm{CO}_{2}$ 响应曲线等表 观生理指标以及内禀生化指标一叶绿素含量, 从光 合表观特性和光合内部机理两个方面系统地探讨 $\mathrm{N}$ 添加对优势种植物的影响以及优势种植物的响应机 制。具体研究目标如下：1)探讨羊草对不同水平 $N$ 添 加的形态和光合生理响应机制; 2)获得有利于羊草生 产的 $\mathrm{N}$ 添加的临界水平的基本数据。以期为草地生态 系统和草地畜牧业的可持续发展提供理论依据。

\section{1 材料和方法}

\section{1 研究地概况}

实验在内蒙古锡林浩特内蒙古大学毛登牧场实 验站 $\left(116.03^{\circ}-116.50^{\circ} \mathrm{E}, 44.80^{\circ}-44.82^{\circ} \mathrm{N}\right)$ 进行。该 地属于温带大陆性气候, 年平均气温0-1 ${ }^{\circ} \mathrm{C}$, 年积 温1 $800{ }^{\circ} \mathrm{C}$, 年降水量300-360 mm, 降水多集中在 6-8月, 无霜期90-115天。土壤以栗钙土为主, 有少 量褐色土, 栗钙土层15-80 cm, 土壤有机质含量为 2\%-3\%, 土质比较肥沃。研究区域优势种为羊草和 大针茅(Stipa grandis)。

\section{2 实验设计}

$\mathrm{N}$ 添加试验设置6个水平, 分别为对照 $(\mathrm{CK}) 、 \mathrm{~N} 1$ $\left(0 \mathrm{~g} \mathrm{~N}^{-\mathrm{m}^{-2}} \cdot \mathrm{a}^{-1}\right) 、 \mathrm{~N} 2\left(2 \mathrm{~g} \mathrm{~N} \cdot \mathrm{m}^{-2} \cdot \mathrm{a}^{-1}\right) 、 \mathrm{~N} 3\left(5 \mathrm{~g} \mathrm{~N} \cdot \mathrm{m}^{-2}\right.$. $\left.\mathrm{a}^{-1}\right) 、 \mathrm{~N} 4\left(10 \mathrm{~g} \mathrm{~N} \cdot \mathrm{m}^{-2} \cdot \mathrm{a}^{-1}\right)$ 和N5 $\left(25 \mathrm{~g} \mathrm{~N} \cdot \mathrm{m}^{-2} \cdot \mathrm{a}^{-1}\right)$, 其设 置依据文献Liu等(2013)。2010年我国北方草原生态 系统的 $\mathrm{N}$ 沉降量为 $22.6 \mathrm{~kg} \mathrm{~N} \cdot \mathrm{hm}^{-2} \cdot \mathrm{a}^{-1}$, 平均每年的增 加量为 $0.42 \mathrm{~kg} \mathrm{~N} \cdot \mathrm{hm}^{-2}$ (Liu et al., 2013)。 N2基本上代 表了2010年的N沉降量, 通过施加N肥来模拟未来几 十年的 $\mathrm{N}$ 沉降。每个处理3组重复, 共计18个处理实 验小区(面积为 $6 \mathrm{~m} \times 6 \mathrm{~m}$ )。 $\mathrm{N}$ 肥为硝酸铵。为确保不 受磷限制, 除了CK外, 各处理小区添加一定量的磷 $\left(1 \mathrm{~g} \mathrm{P}_{2} \mathrm{O}_{5} \cdot \mathrm{m}^{-2}\right)$ 。相邻小区之间设置 $1 \mathrm{~m}$ 的缓冲带。从 2014年开始, 每年6月一次性均匀喷酒。

\section{3 生理生态的测量}

\subsection{1 气体交换参数}

2015年 8月 9-11日, 在无风晴天的 9:00-11:00, 选择生长良好、完全展开的羊草叶片, 用LI-6400便 携式光合测定仪(LI-COR, Lincoln, USA)测定气体 交换参数。每个实验小区 5 个重复, 每个处理(3个小 区)共15个重复。控制叶室内 $\mathrm{CO}_{2}$ 浓度为 $(380 \pm 20)$ $\mu \mathrm{mol} \cdot \mathrm{mol}^{-1}$ 、叶室温度为 $28-30{ }^{\circ} \mathrm{C}$, 用红蓝光源提供 的光合有效辐射 $(P A R)$ 为 $1500 \mu \mathrm{mol} \cdot \mathrm{m}^{-2} \cdot \mathrm{s}^{-1}$, 得到叶 片净光合速率 $\left(P_{\mathrm{n}}\right)$ 、蒸腾速率 $\left(T_{\mathrm{r}}\right)$ 、气孔导度 $\left(G_{\mathrm{s}}\right)$ 和 胞间 $\mathrm{CO}_{2}$ 浓度 $\left(C_{\mathrm{i}}\right)$ 等气体交换参数, 并计算水分利用 效率 $(W U E): W U E=P_{\mathrm{n}} / T_{\mathrm{r}}$ 。

\subsection{2 叶绿素荧光参数}

2015年 8月 9-11日，在无风晴天的 9:00-11:00, 选择生长良好、完全展开的羊草叶片, 用便携式 LI-6400-40脉冲调制式荧光仪 (LI-COR, Lincoln, USA)测定叶绿素苂光参数。每个实验小区 5 个重复, 每个处理共15个重复。暗处理 $40 \mathrm{~min}$ 后, 测量得到 参数最小苂光 $\left(F_{0}\right)$ 、最大苂光 $\left(F_{\mathrm{m}}\right)$ 。在光下光合作用 稳定后测得光下稳定荧光 $\left(F_{\mathrm{s}}\right)$ 、最小苂光 $\left(F_{\mathrm{o}}{ }^{\prime}\right)$ 、最大 荧光 $\left(F_{\mathrm{m}}{ }^{\prime}\right)$ 。PSII最大光化学量子产量: $F_{\mathrm{v}} / F_{\mathrm{m}}=\left(F_{\mathrm{m}}-\right.$ $\left.F_{\mathrm{o}}\right) / F_{\mathrm{m}} 、 \mathrm{PSII}$ 实际光化学量子产量: $\Phi_{\mathrm{PSII}}=\left(F_{\mathrm{m}}{ }^{\prime}-\right.$ $\left.F_{\mathrm{s}}\right) / F_{\mathrm{m}}{ }^{\prime}$, 电子传递速率: $E T R=P A R \times \Phi_{\mathrm{PSII}} \times 0.85 \times$ 0.5 , 光化学淬灭系数: $q_{\mathrm{P}}=\left(F_{\mathrm{m}}{ }^{\prime}-F_{\mathrm{s}}\right) /\left(F_{\mathrm{m}}{ }^{\prime}-F_{\mathrm{o}}{ }^{\prime}\right)$, 非 光化学淬灭系数: $N P Q=F_{\mathrm{m}} / F_{\mathrm{m}}{ }^{\prime}-1$ (Schreiber et al., 1995; Demmig-Adams \& William, 1996)。

\subsection{3 $\mathrm{CO}_{2}$ 响应曲线的测定}

2015年8月 17-21日, 在无风晴天的9:00-11:00, 选择生长良好、完全展开的羊草叶片, 用LI-6400便 携式光合测定仪(LI-COR, Lincoln, USA)测定 $\mathrm{CO}_{2}$ 响 应曲线, 设定温度为 $25{ }^{\circ} \mathrm{C}$, 用红蓝光源提供的 $P A R$ 为 $1500 \mu \mathrm{mol} \cdot \mathrm{m}^{-2} \cdot \mathrm{s}^{-1}, \mathrm{CO}_{2}$ 浓度为 $2000 、 1600$ 、 
1 200、 1 000、800、600、400、300、200、100、 50 和 $0 \mu \mathrm{mol} \cdot \mathrm{mol}^{-1}$ 。每个实验小区测定一条曲线, 每 个处理 3 个重复。 $\mathrm{CO}_{2}$ 浓度在 $200 \mu \mathrm{mol} \cdot \mathrm{mol}^{-1}$ 以下时, 用直角双曲线修正模型拟合所测得的 $\mathrm{CO}_{2}$ 响应曲线, 得到初始羧化效率(CE)(Ye et al., 2012)。采用经典的 Farquhar模型得到最大羧化速率 $\left(V_{\mathrm{cmax}}\right)$ 和最大电子传 递速率 $\left(J_{\max }\right)$, 并计算 $J_{\max } / V_{\text {cmax }}$ (Long \& Bernacchi, 2003)。

\subsection{4 生长指标}

2015年8月9-11日, 在每个N元素添加处理下的 样地中随机选择 $1 \mathrm{~m} \times 1 \mathrm{~m}$ 样方收取地上生物量, 每 个处理 5 个重复。叶片含水量与光合参数测定同步进 行, 选取长势良好的叶片, 在相同部位剪取一定量 叶片, 称量鲜质量后于 $60{ }^{\circ} \mathrm{C}$ 烘干至恒质量称量干质 量, 采用LI-3000A 叶面积仪(LI-COR, Lincoln, USA) 测定叶面积。计算叶片含水量以及比叶质量( LMA, 单位面积叶干质量)。叶片含水量 $=($ 鲜质量 $-干$ 质 量)/鲜质量 $\times 100 \%$ 。烘干后的叶片先粉碎研磨, 再 通过 40 目网篮, 采用 $\mathrm{C} / \mathrm{N}$ 元素分析仪 (CHN-600, Leco, Saint Joseph, USA)进行全N含量的测定(丁小 慧等, 2012)。

\subsection{5 叶绿素含量}

采集与植物光合测定同一部位的叶片, 迅速放 于液氮中带回实验室用于叶绿素以及类胡萝卜素含 量的测定, 每个处理 5 个重复。采用 $95 \%$ 乙醇来提取 叶绿素, 用756PC型紫外分光光度计(上海菁华科技 仪器有限公司)测定(王学奎, 2006)叶绿素含量。

\subsection{6 土壤状况}

施肥前, 在试验地的表层土壤 $(0-30 \mathrm{~cm})$ 取土样, 装进塑封袋, 共6个重复, 带回实验室做全 $\mathrm{N}$ 和全 $\mathrm{C}$ 的测定 (方法同叶片的元素测定), 采用连续流动分 析仪(AutoAnalyzer III, Bran + Luebbe GmbH, Norderstedt, Germany)进行全P、全K和全 $S$ 的测定( $\mathrm{Li}$ et al., 2012)。施 $\mathrm{N}$ 后, 不同处理样地取0-30 cm土壤, 装塑封袋带回实验室。每个小区取两个重复, 每个
表1 样地的土壤特性(平均值土标准误差, $n=6$ )

Table 1 Soil properties of plots (mean $\pm S E, n=6$ )

\begin{tabular}{lllll}
\hline 全氮 & 全磷 & 全碳 & 全钾 & 全硫 \\
$\mathrm{TN}\left(\mathrm{g} \cdot \mathrm{kg}^{-1}\right)$ & $\mathrm{TP}\left(\mathrm{g} \cdot \mathrm{kg}^{-1}\right)$ & $\mathrm{TC}\left(\mathrm{g} \cdot \mathrm{kg}^{-1}\right)$ & $\mathrm{TK}\left(\mathrm{g} \cdot \mathrm{kg}^{-1}\right)$ & $\mathrm{TS}\left(\mathrm{g} \cdot \mathrm{kg}^{-1}\right)$ \\
\hline $1.43 \pm 0.03$ & $0.36 \pm 0.01$ & $21.65 \pm 0.53$ & $22.71 \pm 0.39$ & $0.24 \pm 0.01$ \\
\hline
\end{tabular}

$\overline{\mathrm{TN}}$, total nitrogen; TP, total phosphorus; TC, total carbon; TK, total kalium; TS, total sulfur.

处理共6个重复。土壤含水量的测定采取烘箱烘干的 方法, 在 $65{ }^{\circ} \mathrm{C}$ 烘至恒质量。土壤状况见表 1 , 不同处 理土壤含水量见表2。

\section{4 数据统计分析}

运用SPSS 13.0软件对数据进行分析, 为了解不 同 $\mathrm{N}$ 处理间是否存在显著性差异，对各施 $\mathrm{N}$ 处理的 地上生物量、LMA、叶片含水量、气体交换参数、 色素含量、苂光参数和生化指标数据进行单因素方 差分析, 采用最小显著差数法 $(L S D)$ 进行多重比较。 统计显著水平均为 $p=0.05$ 。采用 Origin 8.6和 Microsoft Excel 2007软件绘制图表。

\section{2 结果}

\section{1 生长参数及叶片 $\mathrm{N}$ 含量对 $\mathrm{N}$ 添加的响应}

$\mathrm{N}$ 添加对羊草地上生物量有显著影响 (图1A; $p<0.05)$ 。羊草地上生物量随着 $\mathrm{N}$ 添加量的增加而增 加, 其中以 $\mathrm{N} 4$ 处理促进作用最为明显, 极显著地促 进了羊草地上生物量 $(p<0.01)$ 。而N5处理时有降低 趋势, 但与CK之间差异性显著 $(p<0.05)$; 与CK相 比, N2、N3、N4和N5处理下羊草的地上生物量分别 增加了 $23.38 \% 、 33.11 \% 、 45.96 \%$ 和 $37.88 \%$ 。

$\mathrm{N}$ 添加对羊草的叶片 $\mathrm{N}$ 含量有显著影响(图1B; $p$ $<0.05)$ 。随着 $\mathrm{N}$ 添加, 叶片 $\mathrm{N}$ 含量也显著增加; 与 $\mathrm{CK}$ 相比, N2、N3、N4和N5处理下羊草的叶片N含量分 别增加了 $21.08 \% 、 32.35 \% 、 82.84 \%$ 和 $81.86 \%$ 。

$\mathrm{N}$ 添加对羊草 $L M A$ 有显著影响(图1C; $p<0.05$ )。 N2和N3处理显著促进了羊草的LMA $(p<0.05)$, 而 $\mathrm{N} 4$ 和N5处理有下降趋势, 但与CK差异不显著 $(p>$ $0.05) 。 \mathrm{~N} 2 、 \mathrm{~N} 3$ 和N4处理分别比CK增加了 $32.48 \%$ 、 $41.66 \%$ 和 $12.21 \%$, 而N1和N5处理分别比CK降低了

表2 不同施氮水平下样地的土壤含水量 $(W)$ (平均值 \pm 标准误差, $n=6$ )

Table 2 Soil water content $(W)$ of plots under different nitrogen $(N)$ addition levels (mean $\pm S E, n=6$ )

\begin{tabular}{|c|c|c|c|c|c|c|}
\hline 氮处理 $\mathrm{N}$ treatment & CK & N1 & N2 & N3 & N4 & N5 \\
\hline$W(\%)$ & $12.73 \pm 0.41^{\mathrm{a}}$ & $12.83 \pm 0.27^{\mathrm{a}}$ & $10.92 \pm 1.67^{\mathrm{bc}}$ & $10.01 \pm 0.53^{b}$ & $9.61 \pm 0.92^{\mathrm{bc}}$ & $9.11 \pm 0.34^{c}$ \\
\hline
\end{tabular}

doi: 10.17521/cjpe.2016.0128 

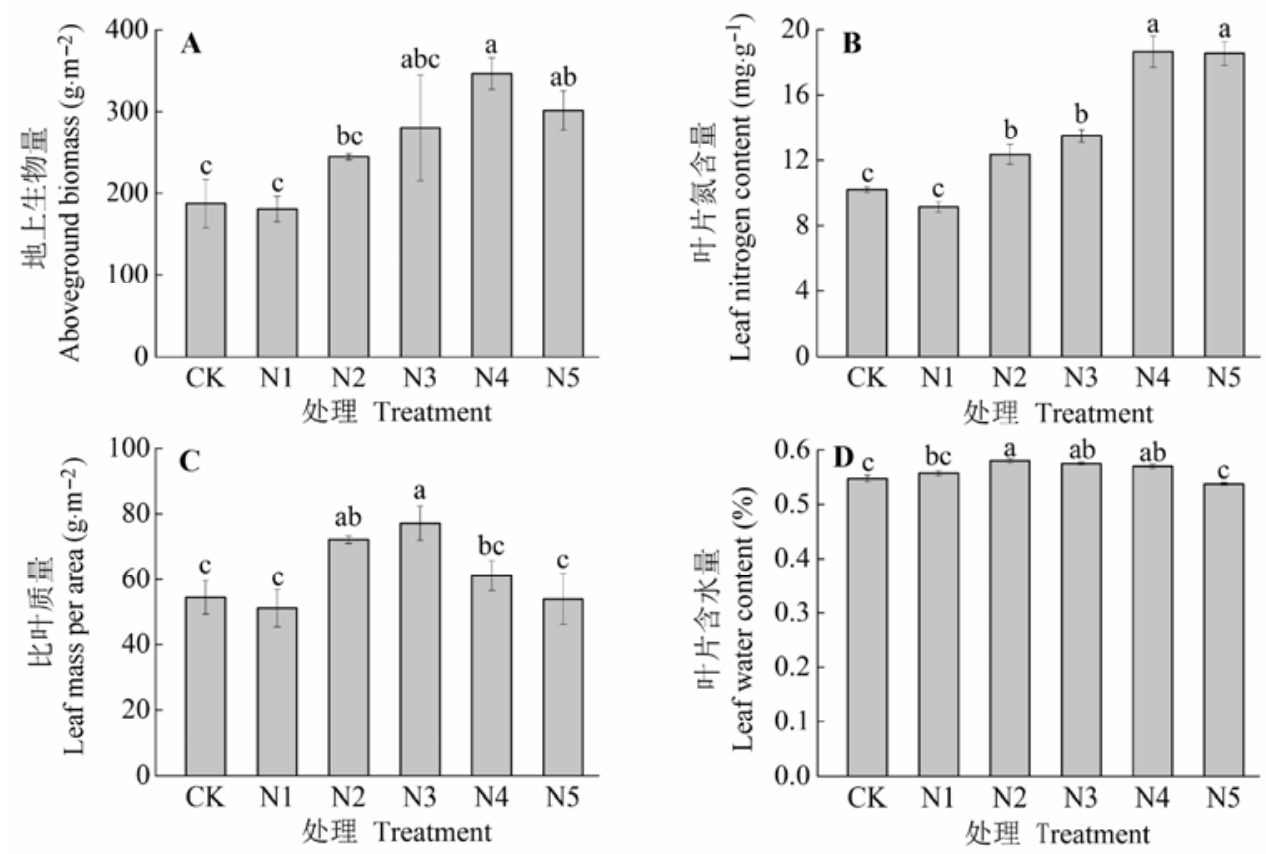

图1 不同施氮水平羊草的地上生物量、叶片氮含量和叶片形态特性(平均值土标准误差)。不同小写字母表示处理间差异显著 $(p<0.05)$ 。处理同表2。

Fig. 1 The aboveground biomass, leaf nitrogen content, and leaf morphological traits of Leymus chinensis under different nitrogen addition levels (mean $\pm S E$ ). Different lowercase letters indicate significant differences among treatments $(p<0.05$ ). Treatment see Table 2.

$6.08 \%$ 和 $0.98 \%$ 。羊草叶片含水量和 $L M A$ 变化趋势一 致, 各处理间差异显著(图1D; $p<0.05)$, 只是变化 程度比较平缓, 说明 $\mathrm{N}$ 添加在一定程度上改变了叶 片的水分机制。

\section{2 叶片气体交换特征对N添加的响应}

$\mathrm{N}$ 添加对羊草 $P_{\mathrm{n}}$ 有极显著影响(图2A; $p<0.01$ )。 在低N水平, $P_{\mathrm{n}}$ 随着 $\mathrm{N}$ 添加梯度而增加, 但在高N水 平下有降低的趋势。 N3 和 44 处理极显著地增加了 $28.07 \%$ 和 $19.19 \%(p<0.01)$, N5处理降低了 $2.31 \%$ 。 $G_{\mathrm{s}} 、 C_{\mathrm{i}}$ 和 $T_{\mathrm{r}}$ 随着 $\mathrm{N}$ 添加量的增加变化趋势基本一致, $\mathrm{N} 1$ 处理轻微增加, 而N2处理急剧增加, 随后逐渐降 低, N2处理增加幅度最大, 并且都与CK的差异性达 到了极显著水平 $(p<0.01)$, 分别增加了 $216.8 \%$ 、 133.5\%和137.5\% (图2B-2D; $p<0.01$ )。WUE随着 $\mathrm{N}$ 添加先降低后升高, 呈现出开口向上的“抛物线”形 (图2E; $p<0.01$ )。与CK相比, N2、N3和N4分别降低 了54.5\%、39.8\%和 $38.0 \%$, 差异性极显著 $(p<0.01)$, 只有N5是增加了 $56.1 \%$, 差异性极显著 $(p<0.01)$ 。 不同的 $\mathrm{N}$ 添加水平下, 羊草的 $P_{\mathrm{n}}$ 和叶片 $\mathrm{N}$ 含量的线 性关系存在差异(图3)。所有处理下的 $P_{\mathrm{n}}$ 和叶片 $\mathrm{N}$ 含 量的关系不显著(图3A; $R^{2}=0.10, p>0.05$ )。而除N5
外，其他处理下的 $P_{\mathrm{n}}$ 和叶片 $\mathrm{N}$ 含量显著的正相关(图 $3 \mathrm{~B} ; R^{2}=0.43, p<0.05$ )。

\section{3 叶片色素含量对 $\mathrm{N}$ 添加的响应}

$\mathrm{N}$ 添加对羊草叶绿素(Chl)有极显著影响(图4A; $p<0.01)$ 。Chl随着施 $\mathrm{N}$ 量先增加后降低。CK、N1、 $\mathrm{N} 2$ 差异不显著 $(p>0.05)$ 。而N3、N4、N5比CK分别 显著增加了 $28.2 \% 、 55.0 \%$ 和 $46.2 \%(p<0.05)$ 。Chl a/b 和类胡夢卜素 $(\mathrm{Car})$ 二者都是随着 $\mathrm{N}$ 添加的增加出现 了微弱的增加然后急剧下降(图4B, C; $p<0.01$ )。与 CK相比, N2和N3使二者微弱地增加, 但是差异性不 显著 $(p>0.05)$; 而N3、N4、N5使二者极显著下降 $(p<$ $0.01)$, 与CK相比, $\mathrm{Chl} \mathrm{a/b}$ 分别降低了 $26.4 \% 、 40.2 \%$ 和 $36.4 \%$, Car分别降低了 $35.0 \%$ 、65.8\%和52.9\%。

\section{4 叶绿素荧光对N添加的响应}

$\mathrm{N}$ 添加对叶绿素荧光参数有极显著影响 (表 3 ; $p<0.01)$ 。 $F_{\mathrm{v}} / F_{\mathrm{m}}$ 在0.80-0.82范围内极显著波动 $(p=$ 0.006)。 $\Phi_{\mathrm{PSII}} 、 E T R$ 和 $q_{\mathrm{P}}$ 都随着 $\mathrm{N}$ 添加量的增加而轻 微地增加, 然后急剧下降; 而 $N P Q$ 起初极显著增加, 然后又极显著下降 $(p<0.01), \mathrm{N} 4$ 和N5与N 1 和N2达 到了极显著差异 $(p<0.01)$, 表现为 “大起大落”的态 势。在N5和CK之间, $\Phi_{\mathrm{PSII}} 、 E T R$ 和 $q_{\mathrm{P}}$ 呈现出极显著 

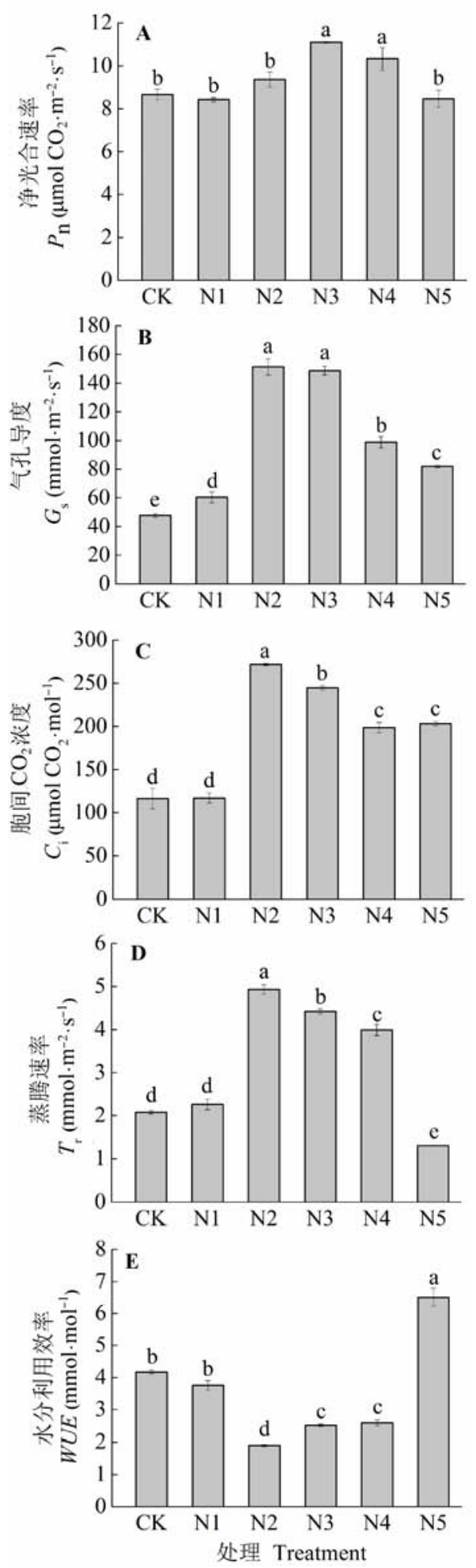

图2 不同施氮水平羊草主要叶片气体交换参数(平均值 \pm 标 准误差)。不同小写字母表示处理间差异显著 $(p<0.05)$ 。处 理同表2。

Fig. 2 The main leaf gas exchange parameters of Leymus chinensis under different nitrogen addition levels (mean $\pm S E$ ). Different lowercase letters indicate significant differences among treatments $(p<0.05) . P_{\mathrm{n}}$, net photosynthetic rate; $G_{\mathrm{s}}$, stomatal conductance; $C_{\mathrm{i}}$, intercellular $\mathrm{CO}_{2}$ concentration; $T_{\mathrm{r}}$, transpiration rate; WUE, water use efficiency. Treatment see Table 2.
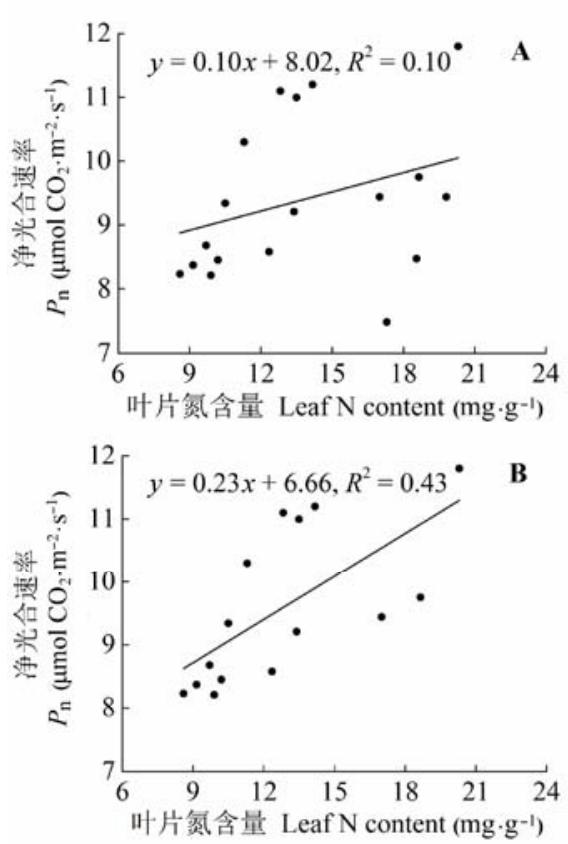

图3 不同施氮水平羊草的净光合速率 $\left(P_{\mathrm{n}}\right)$ 和叶片氮含量的 关系。 $\mathbf{A}$, 净光合速率和叶片氮含量的关系。 $\mathbf{B}$, 净光合速 率和叶片氮含量(N5处理除外)的关系。

Fig. 3 Relationships between net photosynthetic rate $\left(P_{\mathrm{n}}\right)$ and leaf nitrogen $(\mathrm{N})$ content of Leymus chinensis across treatments (A) or across all nitrogen with an exception of the highest $\mathrm{N}$ addition (B).

差异 $(p<0.01)$, 而 $F_{\mathrm{v}} / F_{\mathrm{m}}$ 和 $N P Q$ 并没有呈现出显著 差异 $(p>0.05)$ 。

\section{$2.5 \mathrm{CO}_{2}$ 响应曲线}

$\mathrm{N}$ 添加对所有 $\mathrm{CO}_{2}$ 响应参数有极显著的影响 (表 $4 ; p<0.01)$ 。不同处理的 $C E$ 之间差异显著 $(p<0.05)$, 并在 $\mathrm{N} 3$ 处理出现了高峰; N1-N5处理的 $V_{\mathrm{cmax}}$ 比CK 分别增加了 $55.3 \% 、 36.5 \% 、 225.5 \% 、 138.7 \%$ 和183.6\%, 差异显著 $(p<0.05)$, 也在 $\mathrm{N} 3$ 处理达到了高峰; $J_{\max }$ 变化趋势和 $V_{\mathrm{cmax}}$ 大体相同, N1-N5处理的 $V_{\mathrm{cmax}}$ 比CK 分别增加了 $62.6 \% 、 50.4 \% 、 190.0 \% 、 92.3 \%$ 和 $123.3 \%$; $J_{\max } / V_{\mathrm{cmax}}$ 变化较为缓慢, $\mathrm{N} 1 、 \mathrm{~N} 2$ 处理轻微增加, 而 N3-N5 处理逐渐降低, 并且比CK降低了 $10.9 \%$ 、 $19.4 \%$ 和 $21.2 \%$ 。

\section{3 讨论}

叶片作为植物吸收光能的主要器官, 其光合能 力的强弱直接影响着植物生物量的积累。 $N$ 元素通 常是植物生长和光合作用的主要限制因子(Wang \& Liu, 2014)。本研究中, N添加能够在一定程度上增加 羊草的地上生物量, 尤其是 $\mathrm{N} 4$, 说明施 $\mathrm{N}$ 一定程度 

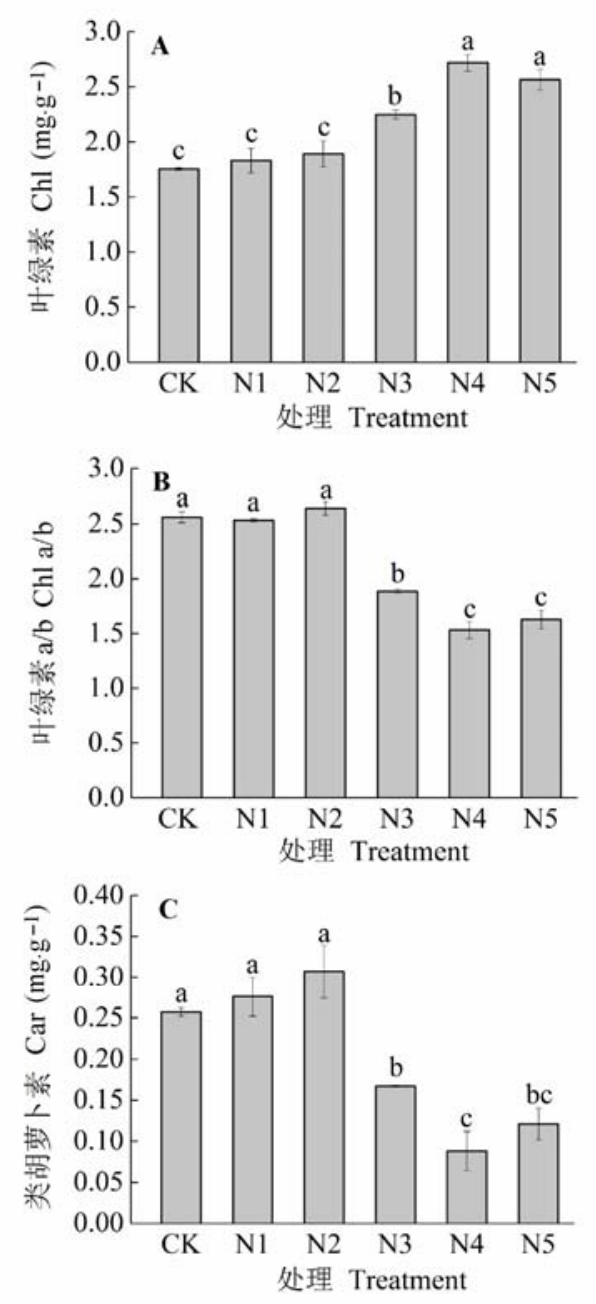

图4 不同施氮水平羊草叶片色素参数(平均值土标准误差)。 不同小写字母表示处理间差异显著 $(p<0.05)$ 。处理同表2。

Fig. 4 The leaf pigment parameters of Leymus chinensis under different nitrogen addition levels (mean $\pm S E$ ). Different lowercase letters indicate significant differences among treatments $(p<0.05)$. Chl, chlorophyll; Car, carotenoids. Treatment see Table 2 .

上可以促进羊草对 $\mathrm{N}$ 元素的吸收而提高光合作用, 提高生物量的积累(Zhao \& Liu, 2009)。然而, 尽管 N5处理显著提高了地上生物量, 但和N4相比有降 低趋势, 可能是羊草过度吸收的 $\mathrm{N}$ 元素形成 $\mathrm{NH}_{4}{ }^{+}$, 扰乱细胞内 $\mathrm{N} 、 \mathrm{P}$ 代谢而使生物量降低(Du et al., 2014)。说明适量的 $N$ 添加促进植物生长, 而当 $\mathrm{N}$ 的 添加水平达到 $25 \mathrm{~g} \mathrm{~N} \cdot \mathrm{m}^{-2} \cdot \mathrm{a}^{-1}$ 时, 对羊草的“助长效 应”有所抑制。

$L M A$ 是一个衡量植物种相对生长速率的重要参 数, 代表叶片光合性能(Lambers \& Poorter, 1992)。 较薄的叶片只需要较少的光合组织就能增加光合能 力, 植物在养分缺乏的条件下可以通过 $L M A$ 的降低
而实现快速生长(Guo et al., 2014)。本研究中, CK和 $\mathrm{N} 1$ 处理下的羊草基本处于 $\mathrm{N}$ 营养缺乏的状态, 但其 通过降低 $L M A$ 来适应养分不足的外界环境。而随着 $\mathrm{N}$ 的添加 $L M A$ 显著增加, $L M A$ 的增加有利于叶绿体 更容易接触胞间 $\mathrm{CO}_{2}$, 有效地获得 $\mathrm{CO}_{2}$, 增加 $P_{\mathrm{n}}(\mathrm{Ki}-$ taoka et al., 2009)。N添加下LMA的变化会因土壤状 况和物种的不同而不同(Ülo \& Kull, 2003)。

$\mathrm{N}$ 添加能够影响植物光合作用的过程以及相关 的气体交换参数(Grassi et al., 2002; Chen et al., 2005)。N元素是光合酶、可溶性蛋白质和光合色素 的组成成分, 施 $\mathrm{N}$ 能够增加叶片的 $G_{\mathrm{s}}$, 促进 $\mathrm{CO}_{2}$ 向叶 肉细胞的扩散和供应, 从而增加植被的 $P_{\mathrm{n}}$, 而 $\mathrm{N}$ 添 加引起光合速率增加的原因有气孔因素和非气孔因 素(Chen et al., 2005; 肖胜生等, 2010)。本研究中, 适量的 $\mathrm{N}$ 添加使 $G_{\mathrm{s}}$ 增加, 而 $C_{\mathrm{i}}$ 和 $C E$ 也相应增加, 说 明适量的 $\mathrm{N}$ 添加导致 $P_{\mathrm{n}}$ 的增加可能是因为 $G_{\mathrm{s}}$ 和羧化 能力增加的共同作用。N5处理时, $P_{\mathrm{n}}$ 随着 $G_{\mathrm{s}}$ 的降低 而降低, 但是 $C_{\mathrm{i}}$ 并没有显著下降, $C E$ 却显著降低, 说明 $P_{\mathrm{n}}$ 的降低并不是 $G_{\mathrm{s}}$ 降低而产生的结果, 应该是 叶肉细胞羧化能力降低引起的结果。植物的光合能 力和叶片 $\mathrm{N}$ 含量存在显著的正相关关系(Moon et al., 2015)。本文中二者相关性随着施N水平的增加而变 化, 其中 CK到 N4处理下二者表现为显著的正相关 关系 $\left(R^{2}=0.43, p<0.05\right)$, 而CK到N5处理下二者的 关系不显著 $\left(R^{2}=0.10, p>0.05\right)$ 。这说明随着施 $\mathrm{N}$ 的 增加(CK到 $N 4)$, N较多地分配给光合器官, 进而提 高了光合能力, 而大量施N (N5)后N可能更多地分 配到细胞壁而非光合器官, 从而降低了光合酶的活 性, 不利于光合能力的增加(Onoda et al., 2004; Moon et al., 2015)。同时, 过量供 $\mathrm{N}$ 导致植株体内营 养失衡, 也会导致 $\mathrm{N}$ 代谢加强, 与碳同化竞争光合 作用中光反应产生的同化力(ATP和NADPH), 这会 导致光合碳同化速率降低, 进而引起地上生物量的 减少(曹翠玲等, 1999; 李德军等, 2004)。高N时(N5), $G_{\mathrm{s}} 、 T_{\mathrm{r}}$ 和叶片含水量显著降低, 而WUE显著增加, 说 明羊草的叶片在大量施N后可以优先提高WUE而不 是把有限的水分用于碳固定, 这可能是羊草在适应 高N施肥下的一种权衡机制(Guo et al., 2014)。另外, 土壤含水量在高 $\mathrm{N}$ 时有下降的趋势, 这可能是因为 施 $\mathrm{N}$ 后地上生物量显著增加, 叶片生物量也随之增 加, 植物需要更多的水分来满足其生长的需要, 降 低了土壤含水量, 从而表现出叶片含水量的降低。 
表3 不同施氮水平下羊草叶绿素菼光特性(平均值土标准误差)

Table 3 Chlorophyll a fluorescence characteristics of Leymus chinensis under different nitrogen addition levels (mean \pm SE)

\begin{tabular}{|c|c|c|c|c|c|}
\hline $\begin{array}{l}\text { 氮处理 } \\
\mathrm{N} \text { treatment }\end{array}$ & $\begin{array}{c}\text { 最大光化学量子产量 } \\
F_{\mathrm{v}} / F_{\mathrm{m}} \\
\end{array}$ & $\begin{array}{c}\text { 实际光化学量子产量 } \\
\Phi_{\mathrm{PSII}} \\
\end{array}$ & $\begin{array}{c}\text { 电子传递速率 } \\
\operatorname{ETR}\left(\mu \mathrm{mol} \cdot \mathrm{m}^{-2} \cdot \mathrm{s}^{-1}\right) \\
\end{array}$ & $\begin{array}{c}\text { 光化学淬灭系数 } \\
q_{\mathrm{p}} \\
\end{array}$ & $\begin{array}{c}\text { 非光化学淬灭系数 } \\
N P Q \\
\end{array}$ \\
\hline CK & $0.81 \pm 0.002^{\mathrm{c}}$ & $0.23 \pm 0.001^{\mathrm{a}}$ & $153.0 \pm 0.82^{\mathrm{a}}$ & $0.54 \pm 0.002^{\mathrm{b}}$ & $2.63 \pm 0.05^{\mathrm{c}}$ \\
\hline N1 & $0.80 \pm 0.001^{\mathrm{c}}$ & $0.23 \pm 0.003^{\mathrm{a}}$ & $156.9 \pm 2.02^{\mathrm{a}}$ & $0.55 \pm 0.003^{\mathrm{ab}}$ & $3.08 \pm 0.05^{\mathrm{a}}$ \\
\hline N2 & $0.82 \pm 0.002^{\mathrm{a}}$ & $0.23 \pm 0.004^{\mathrm{a}}$ & $157.0 \pm 2.80^{\mathrm{a}}$ & $0.59 \pm 0.010^{\mathrm{a}}$ & $3.11 \pm 0.05^{\mathrm{a}}$ \\
\hline N3 & $0.82 \pm 0.002^{\mathrm{ab}}$ & $0.24 \pm 0.009^{\mathrm{a}}$ & $161.9 \pm 6.18^{\mathrm{a}}$ & $0.54 \pm 0.008^{b}$ & $2.82 \pm 0.05^{\mathrm{b}}$ \\
\hline N4 & $0.81 \pm 0.004^{\mathrm{c}}$ & $0.19 \pm 0.010^{\mathrm{b}}$ & $127.3 \pm 6.77^{\mathrm{b}}$ & $0.46 \pm 0.016^{\mathrm{c}}$ & $2.74 \pm 0.09^{\mathrm{bc}}$ \\
\hline N5 & $0.81 \pm 0.003^{\mathrm{abc}}$ & $0.17 \pm 0.003^{\mathrm{b}}$ & $117.0 \pm 1.62^{\mathrm{b}}$ & $0.44 \pm 0.004^{\mathrm{c}}$ & $2.79 \pm 0.05^{\mathrm{bc}}$ \\
\hline
\end{tabular}

不同小写字母表示处理间差异显著 $(p<0.05)$ 。处理同表2。

$E T R$, electron transport rate; $F_{\mathrm{v}} / F_{\mathrm{m}}$, maximum photochemical efficiency; $\Phi P S I I$, actual quantum yield; $N P Q$, non-photochemical quenching coefficient; $q_{P}$, photochemical quenching coefficient. Different lower case letters indicate significant differences among treatments $(p<0.05)$. Treatment see Table 2 .

表4 不同施氮水平下羊草叶片光合能力特性(平均值土标准误差)

Table 4 Photosynthetic capacity characteristics of Leymus chinensis under different nitrogen addition levels (mean \pm SE)

\begin{tabular}{|c|c|c|c|c|}
\hline $\begin{array}{l}\text { 氮处理 } \\
\mathrm{N} \text { treatment }\end{array}$ & $\begin{array}{c}\text { 初始羧化效率 } \\
C E\left(\mathrm{~mol} \cdot \mathrm{m}^{-2} \cdot \mathrm{s}^{-1}\right)\end{array}$ & $\begin{array}{c}\text { 最大䍨化速率 } \\
V_{\mathrm{cmax}}\left(\mu \mathrm{mol} \cdot \mathrm{m}^{-2} \cdot \mathrm{s}^{-1}\right)\end{array}$ & $\begin{array}{l}\text { 最大电子传递速率 } \\
J_{\max }\left(\mu \mathrm{mol} \cdot \mathrm{m}^{-2} \cdot \mathrm{s}^{-1}\right)\end{array}$ & $J_{\max } / V_{\text {cmax }}$ \\
\hline CK & $0.005 \pm 0.0002^{\mathrm{f}}$ & $16.83 \pm 0.49^{\mathrm{e}}$ & $16.48 \pm 0.48^{\mathrm{e}}$ & $0.98 \pm 0.03^{b}$ \\
\hline $\mathrm{N} 1$ & $0.015 \pm 0.0004^{\mathrm{d}}$ & $26.14 \pm 0.75^{\mathrm{d}}$ & $26.79 \pm 0.77^{\mathrm{d}}$ & $1.02 \pm 0.03^{\mathrm{ab}}$ \\
\hline N2 & $0.018 \pm 0.0005^{c}$ & $22.98 \pm 0.66^{\mathrm{d}}$ & $24.79 \pm 0.72^{\mathrm{d}}$ & $1.08 \pm 0.03^{\mathrm{a}}$ \\
\hline N3 & $0.045 \pm 0.0013^{\mathrm{a}}$ & $54.79 \pm 1.58^{\mathrm{a}}$ & $47.80 \pm 1.38^{\mathrm{a}}$ & $0.87 \pm 0.03^{c}$ \\
\hline N4 & $0.030 \pm 0.0009^{b}$ & $40.18 \pm 1.16^{\mathrm{c}}$ & $31.69 \pm 0.91^{\mathrm{c}}$ & $0.79 \pm 0.02^{d}$ \\
\hline N5 & $0.010 \pm 0.0003^{\mathrm{e}}$ & $47.73 \pm 1.38^{\mathrm{b}}$ & $36.80 \pm 1.06^{\mathrm{b}}$ & $0.77 \pm 0.02^{\mathrm{d}}$ \\
\hline
\end{tabular}

不同小写字母表示处理间差异显著 $(p<0.05)$ 。处理同表2。

$C E$, carboxylation efficiency; $J_{\max }$, maximum electron transport rate; $V_{\mathrm{cmax}}$, maximum carboxylation rate. Different lowercase letters indicate significant differences among treatments $(p<0.05)$. Treatment see Table 2 .

叶绿体为光合作用的物质合成提供了场所，而 Chl含量直接影响着光合强度(袁颖红等, 2009)。本 研究中, Chl的含量随着N添加先逐渐增加然后降低 (N5), 这和 $P_{\mathrm{n}}$ 的变化趋势基本一致。说明Chl的增加 可以增加 $P_{\mathrm{n}}$, 而 $\mathrm{N} 5$ 处理时 Chl 降低可能是高浓度 $\mathrm{N}$ 素处理下由于叶片营养元素平衡被打破导致叶绿素 含量有所降低或是过多的 $\mathrm{N}$ 元素被同化成氨基酸或 者多胺, 而不是分配给Chl (肖胜生等, 2010; Bubier et al., 2011)。Chl b是捕光色素复合体II (LHCII)的重 要组成部分, 起到了维持LHCII稳定性的作用, 而 $\mathrm{Chl} \mathrm{a} / \mathrm{b}$ 代表了LHCII所占叶绿素总量中的比重, N添 加超过N2处理时, Chl a/b急剧下降, 说明N添加使 LHCII含量增加, 可以把捕获的能量迅速传至反应 中心, 保障碳固定所需的能量(ATP和NADPH)(郭春 爱等, 2006; 李磊等, 2011)。而低N处理(CK到N2)比 高N处理叶绿素含量降低, Chl a/b 升高, 降低了对光 能的捕获, 同时Car含量增加, 起到一定耗散过剩光 能的作用, 避免光合机构遭受破坏, 这可能是羊草 适应低N生境的一种自我调节机制(González et al., 2007)。
叶绿素苂光提供了光合器官功能和光合作用强 度的信息(Zhao \& Liu, 2009)。本研究中, $F_{\mathrm{v}} / F_{\mathrm{m}}$ 在 0.80-0.82范围波动, 介于 $0.80-0.85$ 之间, 表明羊草 的叶片都是处于健康状态, N添加并没有对光合器 官造成伤害(李晓等, 2006)。低N处理时, $N P Q$ 随着施 $\mathrm{N}$ 量增加显著增加时, $\Phi_{\mathrm{PSII}}$ 出现了轻微的增加, 这可 能是由于施 N导致Chl a/b轻微增加, Chl a直接被光 能激发的分子较多, 引起 $q_{\mathrm{P}}$ 的增加, 激发了更多反 应中心的电荷分离, 而PSII原初电子受体 $\left(\mathrm{Q}_{\mathrm{A}}\right)$ 有限, 势必会出现过剩的激发能, 这就需要 NPQ增加来释 放过多的激发能来保护光合机构, 而较高的ETR也 可证明这一点(Boussadia et al., 2008)。而适量的N添 加, 可以增强叶片对光能的捕获能力, 提高PSII活 性以及光化学效率, 有利于植株把所捕获的光能更 有效地用于光合作用, 从而促进PSII量子效率和光 合速率的提高(郭天财等, 2004)。高N处理(N5)时, $\Phi_{\mathrm{PSII}}$ 和 $q_{\mathrm{P}}$ 急剧下降, 而 $N P Q$ 有上升的趋势。为了维 持光合内部电子传递与Rubisco对还原力需求之间 的平衡, $\Phi_{\mathrm{PSII}}$ 下降以达到PSII的功能下调的目的(王 海珍等, 2014)。说明N5处理使羊草叶片用于电子传 
递的能量占PSII所吸收光能的比例降低, 导致天线 色素光能转换效率和PSII反应中心开放程度降低, PSII反应中心积累过剩的激发能, 从而降低ETR, 导致ATP和NADHP的合成受阻, 限制羧化效率和 RuBP的再生, 降低光合能力, 而为了使PSII不受伤 害, 通过增加 Car 和 $N P Q$ 来耗散多余的激发能 (González et al., 2007; Boussadia et al., 2008; 王海 珍等, 2014)。

$C E$ 反映了Rubisco的活性大小及含量多少。 $V_{\mathrm{cmax}}$ 是表征植物光合能力的重要参数, 对光合速率 起着决定作用。 $J_{\max }$ 是最大电子传递速率, 代表着 RuBP的再生速率(Warren et al., 2003; 张彦敏和周 广胜, 2012)。由于植物碳同化受到Rubisco活性、

$\mathrm{RuBP}$ 的再生以及光合电子传递和磷酸化的活性等 多方面的影响, 可以用 $C E 、 V_{\mathrm{cmax}}$ 和 $J_{\max }$ 来代表碳同 化程度。本研究中, $C E$ 和 $V_{\mathrm{cmax}}$ 随着施 $\mathrm{N}$ 量增加先增 加后降低, 并在N3处理出现了最大值, 说明适量N 添加提高Rubisco的活性和含量, 促进光合作用光 反应阶段产生的激发能更多地向光反应方向分配, 这就为碳同化提供了基础物质(ATP和NADPH), 使 羧化速率增加, 进而增加了光合能力, 并促进光合 产物的积累(张绪成等, 2010)。RuBP再生需要还原 力 (ATP和NADPH) 的积累, 并且反映了光合电子传 递和光合磷酸化活性的大小, $\mathrm{N}$ 素添加使羧化速率 增加的同时, 也使RuBP的再生速率提高(王海珍等, 2014)。高N (N5)处理时, $C E$ 显著降低, 进一步说明 引起 $P_{\mathrm{n}}$ 降低的原因是叶肉细胞羧化能力的降低而不 是由于 $G_{s}$ 降低。植物为了保证 $\mathrm{N}$ 在酶系统(Rubisco) 和光捕获能力 (Chl)之间的平衡, 可以实现 $\mathrm{N}$ 的最优 分配, 而叶 $\mathrm{N}$ 在Rubisco 和 Chl之间的分配比例是羧 化速率和RuBP再生限制同化速率的重要决定因素, 可用 $J_{\max } / V_{\mathrm{cmax}}$ 代表内部Rubisco活性和电子传递的 平衡(Wullschleger et al., 1993; Grassi et al., 2002)。 $J_{\max } / V_{\mathrm{cmax}}$ 与 $L M A$ 变化趋势相同, 在低 $\mathrm{N}$ 处理时, 随 着 $\mathrm{N}$ 添加, $J_{\max } / V_{\mathrm{cmax}}$ 逐渐增大, $L M A$ 较大, 说明叶片 较厚, 此时植物会把更多的 $\mathrm{N}$ 分配到非光合组织(如 细胞壁), 而导致较少的 $\mathrm{N}$ 分配给光合组织, 这表明 分配给羧化系统的 $\mathrm{N}$ 较少, 最终导致 $P_{\mathrm{n}}$ 差异不显著 (CK、N1、N2) (Wullschleger et al., 1993)。超过N2 之后, $J_{\max } / V_{\mathrm{cmax}}$ 开始逐渐降低, 使更多的 $\mathrm{N}$ 分配给羧 化系统, 增加翔化效率, 利于 $P_{\mathrm{n}}$ 的增加。 $\mathrm{N} 5$ 处理时, 超过植物正常需求的N分配给Rubisco以蛋白质的形
式储存起来, 并不表现出强烈的羧化能力, 最终使 $P_{\mathrm{n}}$ 显著降低(Grassi et al., 2002)。

\section{4 结论}

内蒙古温带草原优势种羊草的生长受到 $\mathrm{N}$ 元素 的限制, 并且尚未达到“ $N$ 饱和”。适量的N添加可以 显著提高羊草的光合能力, 但并不是随着 $\mathrm{N}$ 添加的 增加而一直增加, 而是表现为“适量促进, 过量抑 制”。影响植物的光合作用有多种因素, 而N添加通 过影响光合作用的各个环节来影响羊草的生长。低 $\mathrm{N}$ 处理(CK和N1)时, 羊草通过降低 $L M A$ 来获得一定 的光能, 为了防止光合机构受伤害, 增加 Car和 $N P Q$ 耗散过剩激发能, 来适应低 $\mathrm{N}$ 生境; 适量的 $\mathrm{N}$ 添加使 $G_{\mathrm{s}}$ 和羧化能力共同作用而显著增加 $P_{\mathrm{n}}$, 进而提高生 物量的积累; 过量的 N添加(N5和N4相比)引起 $P_{\mathrm{n}}$ 降 低的主要原因是羧化能力的降低, 说明过量的 $\mathrm{N}$ 添 加对羊草的光合能力有一定的抑制作用。尽管N5和 N4处理的地上生物量差异不显著, 但N5处理的地 上生物量有所降低, 而从生理指标上看, 这种降低 趋势更明显, 可能是施 $\mathrm{N}$ 年限较短 (为期两年)对地 上生物量的抑制作用并没有完全显现出来, 因此, 需要进一步探讨长期施 $\mathrm{N}$ 对羊草光合特性的影响。在 内蒙古温带草原, 羊草的最适施 $\mathrm{N}$ 量是 5-10 g $\mathrm{N} \cdot \mathrm{m}^{-2} \cdot \mathrm{a}^{-1}$ 。由于每年 $\mathrm{N}$ 沉降平均增加量为 $0.41 \mathrm{~kg}$ $\mathrm{N} \cdot \mathrm{hm}^{-2}$, 我们可以预测在未来的几十年内大气 $\mathrm{N}$ 沉降 对羊草地上生物量能够起到一定程度的促进作用。

基金项目 国家自然科学基金(41571048)、国家重 点基础研究发展计划(973计划) (2014CB138803)和 国家重点研发计划(2016YFC0500502)。

\section{参考文献}

Aber JD, Goodale CL, Ollinger SV, Smith ML, Magill AH, Martin ME (2003). Is nitrogen deposition altering the nitrogen status of northern forests? Revista Médica De Chile, 53, 158-167.

Anderson TM, Dong Y, Mcnaughton SJ (2006). Nutrient acquisition and physiological responses of dominant Serengeti grasses to variation in soil texture and grazing. Journal of Ecology, 94, 1164-1175.

Bai WM, Wang ZW, Chen QS, Zhang WH, Li LH (2008). Spatial and temporal effects of nitrogen addition on root life span of Leymus chinensis in a typical steppe of Inner Mongolia. Functional Ecology, 22, 583-591.

Bai X, Cheng JH, Zheng SX, Zhan SX, Bai YF (2014). Ecophysiological responses of Leymus chinensis to nitrogen 
and phosphorus additions in a typical steppe. Chinese Journal of Plant Ecology, 38, 103-115. (in Chinese with English abstract) [白雪, 程军回, 郑淑霞, 詹书侠, 白永 飞 (2014). 典型草原建群种羊草对氮磷添加的生理生 态响应. 植物生态学报, 38, 103-115.]

Bai YF, Wu JG, Clark CM, Naeem S, Pan QM, Huang JH, Zhang LX, Han XG (2009). Tradeoffs and thresholds in the effects of nitrogen addition on biodiversity and ecosystem functioning: Evidence from Inner Mongolia grasslands. Global Change Biology, 16, 358-372.

Boussadia O, Mariem FB, Mechri B, Braham W, Braham M, Hadj SBE (2008). Response to drought of two olive tree cultivars (cv Koroneki and Meski). Scientia Horticulturae, 116, 388-393.

Bubier JL, Smith R, Juutinen S, Moore TR, Minocha R, Long S, Minocha S (2011). Effects of nutrient addition on leaf chemistry, morphology, and photosynthetic capacity of three bog shrubs. Oecologia, 167, 355-368.

Cao CL, LI SX, Miao F (1999). The Research situation about effects of nitrogen on certain physiological and biochemical process in plants. The Journal of Northwestern Agricultural University, 20(4), 99-104. (in Chinese with English abstract) [曹翠玲, 李生秀, 苗芳 (1999). 氮素对植 物某些生理生化过程影响的研究进展. 西北农业大学 学报, 20(4), 99-104.]

Chen H, Li DJ, Gurmesa GA, Yu GR, Li LH, Zhang W, Fang HJ, Mo JM (2015). Effects of nitrogen deposition on carbon cycle in terrestrial ecosystems of China: A metaanalysis. Environmental Pollution, 206, 352-360.

Chen SP, Bai YF, Zhang L, Han X (2005). Comparing physiological responses of two dominant grass species to nitrogen addition in Xilin River Basin of China. Environmental \& Experimental Botany, 53, 65-75.

Chen ZZ, Wang SP (2000). The Typical Grassland Ecosystem in China. Science Press, Beijing. (in Chinese) [陈佐忠, 汪 诗平 (2000). 中国典型草原生态系统. 科学出版社, 北 京.]

Clark CM, Tilman D (2008). Loss of plant species after chronic low-level nitrogen deposition to prairie grasslands. Nature, 451, 712-715.

Demmig-Adams B, William W (1996). The role of xanthophyll cycle carotenoids in the protection of photosynthesis. Trends in Plant Science, 1, 21-26.

Ding XH, Luo SZ, Liu JW, Li K, Liu GH (2012). Longitude gradient changes on plant community and soil stoichiometry characteristics of grassland in Hulunbeir. Acta Ecologica Sinica, 11, 3467-3476. (in Chinese with English abstract) [丁小慧, 罗淑政, 刘金巍, 李鬼, 刘国华 (2012). 呼伦贝尔草地植物群落与土壤化学计量学特征 沿经度梯度变化. 生态学报, 11, 3467-3476.]

Du E, Liu X, Fang J (2014). Effects of nitrogen additions on biomass, stoichiometry and nutrient pools of moss Rhytidium rugosum in a boreal forest in Northeast China. Environmental Pollution, 188, 166-171.

Du J, Shu S, Shao Q, An Y, Zhou H, Guo S, Sun J (2016). Mitigative effects of spermidine on photosynthesis and carbon-nitrogen balance of Cucumber seedlings under $\mathrm{Ca}\left(\mathrm{NO}_{3}\right)_{2}$ stress. Journal of Plant Research, 129, 1-13.

González JA, Gallardo MG, Boero C, Cruz ML, Prado FE (2007). Altitudinal and seasonal variation of protective and photosynthetic pigments in leaves of the world's highest elevation trees Polylepis tarapacana (Rosaceae). Acta Oecologica, 32, 36-41.

Grassi G, Meir P, Cromer R, Tompkins D, Jarvis PG (2002). Photosynthetic parameters in seedlings of Eucalyptus grandis as affected by rate of nitrogen supply. Plant, Cell \& Environment, 25, 1677-1688.

Guo CA, Liu F, Xu XM (2006). Chlorophyll-b deficient and photosynthesis in plants. Plant Physiology Communications, 42, 967-973. (in Chinese with English abstract) [郭 春爱, 刘芳, 许晓明 (2006). 叶绿素b缺失与植物的光 合作用. 植物生理学通讯, 42, 967-973.]

Guo EH, Hu D, Tian CY, Hu Y, Wang CY, Yu YY (2008). Study on the effects of soil nitrogen and moisture on plant photosynthetic physiological ecology. Journal of Anhui Agriculture Sciences, 26, 11211-11213. (in Chinese with English abstract) [郭二辉, 胡聘, 田朝阳, 胡颖, 王从彦, 于盈盈 (2008). 土壤氮素与水分对植物光合生理生态 的影响研究. 安徽农业科学, 26, 11211-11213.]

Guo TC, Feng W, Zhao HJ, Xue GD, Wang HC, Wang YH, Yao ZJ (2004). Photosynthetic characteristics of flag leaves and nitrogen effects in two winter wheat cultivars with different spike type. Acta Agronomica Sinica, 30(2), 115-121. (in Chinese with English abstract) [郭天财, 冯 伟, 赵会杰, 薛国典, 王化岑, 王永华, 姚战军 (2004). 两种穗型冬小麦品种旗叶光合特性及氮素调控效应. 作物学报, 30(2), 115-121.]

Guo X, Wang RQ, Chang RY, Liang XQ, Wang CD, Luo Y, Guo W (2014). Effects of nitrogen addition on growth and photosynthetic characteristics of Acer truncatum seedlings. Dendrobiology, 72, 151-161.

Kitaoka S, Watanabe Y, Koike T (2009). The effects of cleared larch canopy and nitrogen supply on gas exchange and leaf traits in deciduous broad-leaved tree seedlings. Tree Physiology, 29, 1503-1511.

Krause K, Cherubini P, Bugmann H, Schleppi P (2012). Growth enhancement of Picea abies trees under long-term, low-dose $\mathrm{N}$ addition is due to morphological more than to physiological changes. Tree Physiology, 32, 1471-1481.

Lambers H, Poorter H (1992). Inherent variation in growth rate between higher plants: A search for physiological causes and ecological consequences. Advances in Ecological 
Research, 23, 187-261.

Li DJ, Mo JM, Fang YT, Cai XA, Xue JH, Xu GL (2004). Effects of simulated nitrogen deposition on growth and photosynthesis of Schima superba, Castanopsis chinensis and Cryptocarya concinna seedlings. Acta Ecologica Sinica, 24, 876-882. (in Chinese with English abstract) [李德军, 莫江明, 方运霆, 蔡锡安, 薛璟花, 徐国良 (2004). 模 拟氮沉降对三种南亚热带树苗生长和光合作用的影响. 生态学报, 24, 876-882.]

Li L, Li XY, Lin LS, Wang YJ, Xue W (2011). Comparison of chlorophyll content and fluorescence parameters of six pasture species in two habitats in China. Chinese Journal of Plant Ecology, 35, 672-680. (in Chinese with English abstract) [李否, 李向义, 林丽莎, 王迎菊, 薛伟 (2011). 两种生境条件下 6 种牧草叶绿素含量及苂光参数的比 较. 植物生态学报, 35, 672-680.]

Li LJ, Zeng DH, Mao R, Yu ZY (2012). Nitrogen and phosphorus resorption of Artemisia scoparia, Chenopodium acuminatum, Cannabis sativa, and Phragmites communis under nitrogen and phosphorus additions in a semiarid grassland, China. Plant, Soil \& Environment, 58, 446-451.

Li X, Feng W, Zeng XC (2006). Advances in chlorophyll fluorescence analysis and its uses. Acta Botanica BorealiOccidentalia Sinica, 10, 2186-2196. (in Chinese with English abstract) [李晓, 冯伟, 曾晓春 (2006). 叶绿素 荧光分析技术及应用进展. 西北植物学报, 10, 21862196.]

Li YY, Lü XT, Wang ZW, Zhou C, Han XG (2014). Linking relative growth rates to biomass allocation: The responses of the grass Leymus chinensis to nitrogen addition. Phyton, 83, 283-289.

Liu X, Zhang Y, Han W, Tang A, Shen J, Cui Z, Vitousek P, Erisman J, Goulding K, Christie P, Fangmeier A, Zhang F (2013). Enhanced nitrogen deposition over China. Nature, 494, 459-462.

Liu XJ, Duan L, Mo JM, Du EZ, Shen JL, Lu XK, Zhang Y, Zhou XB, He CN, Zhang FS (2011). Nitrogen deposition and its ecological impact in China: An overview. Environmental Pollution, 159, 2251-2264.

Liu YS, Pan QM, Zheng SX, Bai YF, Han XG (2012). Intra-seasonal precipitation amount and pattern differentially affect primary production of two dominant species of Inner Mongolia grassland. Acta Oecologica, 44, 2-10.

Long SP, Bernacchi CJ (2003). Gas exchange measurements, what can they tell us about the underlying limitations to photosynthesis? Procedures and sources of error. Journal of Experimental Botany, 54, 2393-2401.

Makhnev AK, Makhneva NE (2010). Landscape-ecological and population aspects of the strategy of restoration of disturbed lands. Contemporary Problems of Ecology, 3, 318-322.
Mariotte P, Buttler A, Johnson D, Thébault A, Vandenberghe C (2012). Exclusion of root competition increases competitive abilities of subordinate plant species through root-shoot interactions. Journal of Vegetation Science, 23, 1148-1158.

Moon M, Kang KS, Park IK, Kim T, Kim HS (2015). Effects of leaf nitrogen allocation on the photosynthetic nitrogen-use efficiency of seedlings of three tropical species in Indonesia. Journal of the Korean Society for Applied Biological Chemistry, 58, 1-9.

Nicodemus MA, Salifu FK, Jacobs DF (2008). Growth, nutrition, and photosynthetic response of black walnut to varying nitrogen sources and rates. Journal of Plant Nutrition, 31, 1917-1936.

Onoda Y, Hikosaka K, Hirose T (2004). Allocation of nitrogen to cell walls decreases photosynthetic nitrogen-use efficiency. Functional Ecology, 18, 419-425.

Pan QM, Bai YF, Han XG, Yang JC (2005). Effects of nitrogen addition on a Leymus chinensis population in typical steppe of Inner Mongolia. Acta Phytoecologica Sinica, 29, 311-317. (in Chinese with English abstract) [潘庆民, 白 永飞, 韩兴国, 杨景成 (2005). 氮素对内蒙古典型草原 羊草种群的影响. 植物生态学报, 29, 311-317.]

Peng Q, Qi YC, Dong YS, He YT, Xiao SS (2014). Litter decomposition and the $\mathrm{C}$ and $\mathrm{N}$ dynamics as affected by $\mathrm{N}$ additions in a semi-arid temperate steppe, Inner Mongolia of China. Journal of Arid Land, 6, 432-444.

Schreiber U, Bilger W, Neubauer C (1995). Chlorophyll fluorescence as a nonintrusive indicator for rapid assessment of in vivo photosynthesis. Ecological Studies Analysis \& Synthesis, 100, 49-70.

Sun L, Dong YS, Qi YC, He YT, Peng Q, Liu XC, Jia JQ, Guo SF, Cao CC (2014). Intra- and inter-annual variation of soil microbial and enzymatic response to water and nitrogen addition in a Chinese semi-arid steppe. Journal of Pure and Applied Microbiology, 8, 1339-1351.

Thomas RQ, Canham CD, Weathers KC, Goodale CL (2010). Increased tree carbon storage in response to nitrogen deposition in the US. Nature Geoscience, 3, 13-17.

Ülo N, Kull K (2003). Leaf structure vs. nutrient relationships vary with soil conditions in temperate shrubs and trees. Acta Oecologica, 24, 209-219.

Wallace ZP, Lovett GM, Hart JE, Machona B (2007). Effects of nitrogen saturation on tree growth and death in a mixed-oak forest. Forest Ecology \& Management, 243, 210-218.

Wang G, Liu F (2014). Carbon allocation of Chinese pine seedlings along a nitrogen addition gradient. Forest Ecology \& Management, 334, 114-121.

Wang HZ, Han L, Xu YL, Niu JL (2014). Photosynthetic responses of the heteromorphic leaves in Populus euphratica 
to light intensity and $\mathrm{CO}_{2}$ concentration. Chinese Journal of Plant Ecology, 38, 1099-1109. (in Chinese with English abstract) [王海珍, 韩路, 徐雅丽, 牛建龙 (2014). 胡杨 异形叶光合作用对光强与 $\mathrm{CO}_{2}$ 浓度的响应. 植物生态学 报, 38, 1099-1109.]

Wang RZ (1997). The niche breadths and niche overlaps of main plant populations in Leymus chinensis grassland for grazing. Acta Phytoecologica Sinica, 21, 9-16. (in Chinese with English abstract) [王仁忠 (1997). 放牧影响下羊草 草地主要植物种群生态位宽度与生态位重叠的研究. 植物生态学报, 21, 9-16.]

Wang XK (2006). Principle and Technology of Plant Physiological and Biochemical Experiments. Higher Education Press, Beijing. 134-136. (in Chinese) [王学奎 (2006). 植 物生理生化实验原理和技术. 高等教育出版社, 北京. 134-136.]

Wang YH, He XY, Zhou GS (2002). Study on the responses of Leymus chinensis steppe to grazing in Songnen Plain. Acta Agrestia Sinica, 10, 45-49. (in Chinese with English abstract) [王玉辉, 何兴元, 周广胜 (2002). 放牧强度对羊 草草原的影响. 草地学报, 10, 45-49.]

Warren CR, Adams MA, Chen ZL (2000). Is photosynthesis related to concentrations of nitrogen and Rubisco in leaves of Australian native plants? Functional Plant Biology, 27, 407-416.

Warren CR, Dreyer E, Adams MA (2003). PhotosynthesisRubisco relationships in foliage of Pinus sylvestris in response to nitrogen supply and the proposed role of Rubisco and amino acids as nitrogen stores. Tree, 17, 359-366.

Wullschleger SD (1993). Biochemical limitations to carbon assimilation in $\mathrm{C}_{3}$ plants- $\mathrm{A}$ retrospective analysis of the $A / C_{\mathrm{i}}$ curves from 109 species. Journal of Experimental Botany, 44, 907-920.

Xiao SS, Dong YS, Qi YC, Peng Q, He YT, Liu XC (2010). Effects of mineral fertilizer addition on leaf functional traits and photosynthetic characteristics of Leymus chinensis from a temperate grassland in Inner Mongolia in China. Acta Scientiae Circumstantiae, 30, 2535-2543. (in Chinese with English abstract) [肖胜生, 董云社, 齐玉春, 彭 琴, 何亚婷, 刘欣超 (2010). 内蒙古温带草原羊草叶片 功能特性与光合特征对外源氮输入的响应. 环境科学 学报, 30, 2535-2543.]

Xiao YG, Chen Q, Shan L, Brueck H, Dittert K, Taube F, Schnyder H (2011). Tradeoffs between nitrogen- and water-use efficiency in dominant species of the semiarid steppe of Inner Mongolia. Plant \& Soil, 340, 227-238.

Xu ZZ, Zhou GS (2006). Combined effects of water stress and high temperature on photosynthesis, nitrogen metabolism and lipid peroxidation of a perennial grass Leymus chinen- sis. Planta, 224, 1080-1090.

Yao M, Rui J, Li J, Dai Y, Bai Y, Heděnec P, Wang JM, Zhang SH, Pei KQ, Liu C, Wang YF, He ZL, Frouz J, Li XZ (2014). Rate-specific responses of prokaryotic diversity and structure to nitrogen deposition in the Leymus chinensis steppe. Soil Biology \& Biochemistry, 79, 81-90.

Ye ZP, Yu Q, Kang HJ (2012). Evaluation of photosynthetic electron flow using simultaneous measurements of gas exchange and chlorophyll fluorescence under photorespiratory conditions. Photosynthetica, 50, 472-476.

Yuan YH, Fan HB, Huang QR, Liao YC, Huang RZ (2009). Effects of long-term fertilization on rice photosynthetic traits and water use efficiency. Chinese Journal of Ecology, 28, 2239-2244. (in Chinese with English abstract) [袁 颖红, 刹后保, 黄欠如, 廖迎春, 黄荣珍 (2009). 长期 施肥对水稻光合特性及水分利用效率的影响. 生态学 杂志, 28, 2239-2244.]

Zhan SX, Zheng SX, Wang Y, Bai YF (2016). Response and correlation of above- and below-ground functional traits of Leymus chinensis to nitrogen and phosphorus additions. Chinese Journal of Plant Ecology, 40, 36-47. (in Chinese with English abstract) [詹书侠, 郑淑霞, 王扬, 白永飞 (2016). 羊草的地上-地下功能性状对氮磷施肥梯度的 响应及关联. 植物生态学报, 40, 36-47.]

Zhang J, Han X (2008). $\mathrm{N}_{2} \mathrm{O}$ emission from the semi-arid ecosystem under mineral fertilizer (urea and superphosphate) and increased precipitation in northern China. Atmospheric Environment, 42, 291-302.

Zhang L, Yang YX, Zhan XY, Zhang CJ, Zhou SX, Wu DX (2010). Responses of a dominant temperate grassland plant (Leymus chinensis) to elevated carbon dioxide and nitrogen addition in China. Journal of Environmental Quality, 39, 251-259.

Zhang T, Yang S, Guo R, Guo J (2016). Warming and nitrogen addition alter photosynthetic pigments, sugars and nutrients in a temperate meadow ecosystem. PLOS ONE, 11, e0155375. doi:10.1371/journal.pone.0155375.

Zhang XC, Yu XF, Gao SM (2010). Effects of nitrogen application rates on photosynthetic energy utilization in wheat leaves under elevated atmospheric $\mathrm{CO}_{2}$ concentration. Chinese Journal of Plant Ecology, 34, 1196-1203. (in Chinese with English abstract) [张绪成, 于显枫, 高世铭 (2010). 高大气 $\mathrm{CO}_{2}$ 浓度下氮素对小麦叶片光能利用的 影响. 植物生态学报, 34, 1196-1203.]

Zhang YH, He NP, Zhang GM, Huang JH, Han XG (2013). Nitrogen deposition and Leymus chinensis leaf chlorophyll content in Inner Mongolian grassland. Acta Ecologica Sinica, 33, 6786-6794. (in Chinese with English abstract) [张云海, 何念鹏, 张光明, 黄建辉, 韩兴国 (2013). 氮 沉降强度和频率对羊草叶绿素含量的影响. 生态学报, 33, 6786-6794.] 
Zhang YM, Zhou GS (2012). Advances in leaf maximum carboxylation rate and its response to environmental factors. Acta Ecologica Sinica, 32, 5907-5917. (in Chinese with English abstract) [张彦敏, 周广胜 (2012). 植物叶片最 大羧化速率及其对环境因子响应的研究进展. 生态学 报, 32, 5907-5917.]

Zhang ZY, Gong JR, Liu M, Huang YM, Yan X, Qi Y, Wang YH (2013). Dominant species and ecosystem gas exchange in temperate grassland under different land use patterns. Chinese Journal of Plant Ecology, 37, 718-727. (in Chinese with English abstract) [张梓瑜, 龚吉芯, 刘 敏, 黄永梅, 晏欣, 祁瑜, 王忆慧 (2013). 温带草原不 同土地利用方式下优势种植物和生态系统的气体交换. 植物生态学报, 37, 718-727.]
Zhao C, Liu Q (2009). Growth and photosynthetic responses of two coniferous species to experimental warming and nitrogen fertilization. Canadian Journal of Forest Research, 39, 1-11.

Zhu JT, Li XY, Zhang XM, Lin LS, Yang SG (2010). Nitrogen allocation and partitioning within a leguminous and two non-leguminous plant species growing at the southern fringe of China's Taklamakan Desert. Chinese Journal of Plant Ecology, 34, 1025-1032. (in Chinese with English abstract) [朱军涛, 李向义, 张希明, 林丽莎, 杨尚功 (2010). 塔克拉玛干沙漠南缘豆科与非豆科植物的氮分 配. 植物生态学报, 34, 1025-1032.]

责任编委: 张守仁 责任编辑: 李 敏

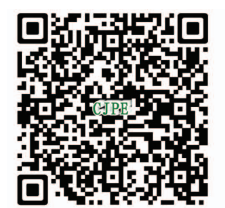

植物生态学报官网

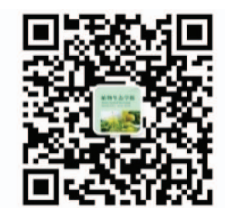

微信订阅号

期刊及学科

相关信息发布

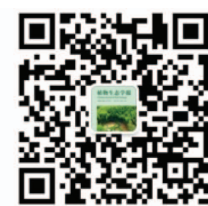

微信服务号

稿件状态查询

全文检索浏览 